\title{
Risk factors for choroidal detachment after trabeculectomy with mitomycin $\mathrm{C}$
}

This article was published in the following Dove Press journal:

Clinical Ophthalmology

10 July 2013

Number of times this article has been viewed

\author{
Akira Hagal \\ Masaru Inatani ${ }^{1,2}$ \\ Kohei Shobayashi' \\ Sachi Kojima' \\ Toshihiro Inouel \\ Hidenobu Tanihara' \\ 'Department of Ophthalmology, \\ Faculty of Life Sciences, Kumamoto \\ University, Kumamoto, Japan; \\ ${ }^{2}$ Department of Ophthalmology, \\ Faculty of Medical Science, University \\ of Fukui, Fukui, Japan
}

Purpose: To evaluate the risk factors for choroidal detachment after trabeculectomy with mitomycin $\mathrm{C}$ (MMC).

Materials and methods: We retrospectively evaluated 420 patients (420 eyes) with glaucoma who underwent trabeculectomy with MMC between June 1, 2005 and December 31, 2010 at Kumamoto University Hospital, Japan. Choroidal detachment after trabeculectomy was defined as a solid-appearing elevation of the retina and choroid. Logistic multivariable analysis was applied to determine the risk factors for choroidal detachment. The following factors were assessed: gender, age, subtypes of glaucoma, eye laterality, history of previous cataract surgery, preoperative intraocular pressure (IOP; mean of three Goldmann applanation readings recorded on different days), postoperative IOP (mean of seven Goldmann applanation readings recorded on 7 consecutive days after trabeculectomy), and postoperative laser suture lysis.

Results: Of the 420 patients, 79 (18.8\%) revealed choroidal detachments. The mean period between trabeculectomy and choroidal detachment was $6.1 \pm 3.6$ days. The mean IOP at the time of the choroidal detachment was $5.5 \pm 3.6 \mathrm{mmHg}$. Age (odds ratio $[\mathrm{OR}]=1.028 /$ year, $P=0.0068)$ and postoperative IOP $(\mathrm{OR}=0.887 / \mathrm{mmHg}, P<0.0001)$ were risk factors for choroidal detachment after trabeculectomy. The subgroup analysis for eyes with open angle glaucoma (201 patients) revealed that age $(\mathrm{OR}=1.060 /$ year, $P=0.0040)$ and postoperative IOP $(\mathrm{OR}=0.898 / \mathrm{mmHg}, P=0.0110)$ were significant risk factors for choroidal detachment after trabeculectomy with MMC.

Conclusion: Among glaucoma patients, older age and lower postoperative IOP are risk factors for choroidal detachment after trabeculectomy with MMC. In eyes with open angle glaucoma, older age and lower postoperative IOP are risk factors for choroidal detachment after trabeculectomy with MMC.

Keywords: choroidal detachment, intraocular pressure, mitomycin C, trabeculectomy

\section{Introduction}

Choroidal detachment is a common complication of trabeculectomy. ${ }^{1}$ Most detachments are transient in nature and occur during the early postoperative period. The incidence of choroidal detachment after trabeculectomy is reported to be $5 \%-44 \%{ }^{1-5}$ Hypotony after trabeculectomy causes fluid to accumulate in the suprachoroidal space, which can consequently lead to choroidal detachment. Some reports suggest that choroidal detachment causes inflammation in the anterior chamber, which is associated with bleb failure after trabeculectomy. ${ }^{3,6}$ To treat patients suffering from persistent choroidal detachments, suprachoroidal fluid can be drained through a sclerotomy. ${ }^{7}$
Correspondence: Masaru Inatani Department of Ophthalmology, Faculty of Medical Science, University of Fukui, 23-3 Shimoaizuki, Matsuoka, Eiheiji, Yoshida, Fukui, 910-I 193, Japan Tel +81776 6I 8403

Fax +81776 6I 8131

Email inatani@u-fukui.ac.jp 
In addition to postoperative hypotony, several patient characteristics are associated with choroidal detachment. ${ }^{7,8}$ However, no large-scale analyses have investigated the risk factors for choroidal detachment after trabeculectomy. The present study was designed to explore this issue in patients who had recently undergone trabeculectomy with mitomycin $\mathrm{C}(\mathrm{MMC})$.

\section{Material and methods Patient population}

We retrospectively reviewed the medical records of 420 consecutive patients with glaucoma who underwent trabeculectomy with MMC at Kumamoto University Hospital, Kumamoto City, Japan, between June 1, 2005 and December 31, 2010. In patients who underwent trabeculectomy with MMC for both eyes, only the eye that was treated first was included in the analysis. There were no exclusion criteria in the retrospective study for systemic disorders or systemic medical treatment. The study was approved by the Institutional Review Board of Kumamoto University Hospital, and all study protocols adhered to the Declaration of Helsinki. In accordance with the Japanese Ministry of Health, Labor and Welfare Guidelines for Clinical Research, patients were informed of the study design through the hospital website.

\section{Surgical procedure}

All trabeculectomies were performed following the same surgical procedure as described previously. ${ }^{9}$ In brief, a conjunctival flap was created by a fornix-based incision; the creation of the scleral flap was a half-layer single flap. The concentration and the incubation of MMC were $0.4 \mathrm{mg} / \mathrm{mL}$ and 4 minutes, respectively. The fistula creation and peripheral iridectomy were performed routinely; 10-0 monofilament nylon sutures were used for the closure of the scleral flap and the conjunctiva. After surgery, a similar topical medical regimen $-0.1 \%$ topical betamethasone, $1 \%$ topical atropine sulfate, and $0.5 \%$ topical levofloxacin - was applied to all the patients.

\section{Main outcome measures}

Our main purpose was to identify the risk factors for choroidal detachment as an early postoperative complication (within 7 days) after trabeculectomy with MMC. Postoperative choroidal detachment was defined as a solid-appearing elevation of the retina and choroid with funduscopic examination.

\section{Statistical analysis}

The JMP version 8 statistical package program (SAS Institute, Inc, Cary, NC, USA) was used for data analysis. Patient characteristics were compared between patients with and without choroidal detachments by using the Mann-Whitney $U$ test or the $\chi^{2}$ test for independence. The following factors were assessed: patient gender, patient age, subtypes of glaucoma, eye laterality, history of previous cataract surgery, preoperative intraocular pressure (IOP; mean of three Goldmann applanation readings recorded on different days), postoperative IOP (mean of seven Goldmann applanation readings recorded on 7 consecutive days after trabeculectomy), the lowest postoperative IOP (Goldmann applanation readings recorded 7 days after trabeculectomy), and postoperative laser suture lysis. Multivariable analysis was performed in conjunction with the logistic analysis. To perform the subgroup analysis among open angle glaucoma patients, patient gender, patient age, subtypes of glaucoma, eye laterality, history of previous cataract surgery, preoperative IOP, postoperative IOP, the lowest postoperative IOP, and postoperative laser suture lysis were compared between the two groups. $P$-values $<0.05$ were considered statistically significant. Data are presented as mean \pm standard deviation.

\section{Results}

A total of 420 patients (420 eyes) met the study criteria. All the patients were Japanese; their baseline characteristics are presented in Table 1. Of these, 79 (18.8\%) presented choroidal detachment after trabeculectomy with MMC. Table 2 presents a comparison between the groups with and without choroidal detachments. The mean period between trabeculectomy and choroidal detachment was $6.1 \pm 3.6$ days, with a mean IOP of $5.5 \pm 3.6 \mathrm{mmHg}$ on the first day of choroidal detachment. The patients in the choroidal detachment group were significantly older than those in the non-choroidal detachment group $(P=0.005)$. Moreover, the mean and lowest postoperative IOP were significantly lower in the choroidal detachment group than the non-choroidal detachment group $(P<0.001)$. However, there were no significant differences between the groups in terms of gender ratio, subtypes of glaucoma, eye laterality, history of previous cataract surgery, or postoperative laser suture lysis. Logistic analysis of these 420 patients (Table 3 ) confirmed that the risk factors for choroidal detachment were older age (odds ratio $[\mathrm{OR}]=1.028 ; P=0.0068)$ and lower postoperative IOP $(\mathrm{OR}=0.887 ; P<0.0001)$. 
Table I Demographic characteristics of patients

\begin{tabular}{ll}
\hline Characteristic & Value (\%) \\
\hline Gender & $29 I(69.3)$ \\
Male & $129(30.7)$ \\
Female & \\
Age, years & $65.0 \pm$ I4.4 \\
Mean \pm SD & $13-90$ \\
Range & \\
Eye laterality & $179(42.6)$ \\
Right & $24 I(57.4)$ \\
Left & \\
Subtype of glaucoma & $112(26.7)$ \\
Primary open angle glaucoma & $108(25.7)$ \\
Neovascular glaucoma & $89(21.2)$ \\
Exfoliation glaucoma & $34(8.1)$ \\
Primary angle closure glaucoma & $77(18.3)$ \\
Secondary glaucoma & $58(13.8)$ \\
$\quad$ Uveitis & $19(4.5)$ \\
$\quad$ Others & \\
Preoperative IOP (mmHg) & $31.4 \pm 9.8$ \\
Mean \pm SD & $13.7-61.0$ \\
Range & \\
History of cataract surgery & $198(47.1)$ \\
Yes & $222(52.9)$ \\
No & \\
Mean IOP between I and 7 days after the surgery (mmHg) & \\
Mean \pm SD & $13.0 \pm 6.8$ \\
Range & $0-38.4$ \\
Yostoperative laser suture lysis & \\
No & $285(67.9)$ \\
\hline
\end{tabular}

Abbreviations: IOP, intraocular pressure; SD, standard deviation.

Table 4 presents a comparison between the choroidal detachment and non-choroidal detachment groups in patients with open angle glaucoma (201 eyes). In total, 39 (19.4\%) patients experienced choroidal detachments. Moreover, the choroidal detachment group comprised significantly older patients $(P=0.005)$ along with reduced mean and lowest postoperative IOP values $(P<0.001)$. Significantly more patients in the nonchoroidal detachment group were treated with laser suture lysis $(P=0.023)$. Furthermore, logistic analysis of these 201 patients (Table 5) demonstrated that the risk factors for choroidal detachment in patients with open angle glaucoma were older age $(\mathrm{OR}=1.060 ; P=0.0040)$ and reduced postoperative IOP $(\mathrm{OR}=0.898 ; P=0.0110)$.

\section{Discussion}

The present study identified the following risk factors for choroidal detachment after trabeculectomy with MMC: older age $(\mathrm{OR}=1.028$ per year increase; $P=0.0068)$ and reduced postoperative IOP $(\mathrm{OR}=0.887 \mathrm{per} \mathrm{mmHg}$ increase; $P<0.0001)$. Subgroup analysis among the 201 patients
Table 2 Comparison of patient data between choroidal detachment and non-choroidal detachment groups

\begin{tabular}{|c|c|c|c|}
\hline \multirow[t]{2}{*}{ Characteristic } & \multicolumn{2}{|l|}{ Value (\%) } & \multirow[t]{2}{*}{$P$-value } \\
\hline & $\begin{array}{l}\text { CD (+) } \\
(n=79)\end{array}$ & $\begin{array}{l}C D(-) \\
(n=34 I)\end{array}$ & \\
\hline Gender & & & 0.540 \\
\hline Male & $57(72.2)$ & $234(68.6)$ & \\
\hline Female & $22(27.8)$ & $107(3 \mid .4)$ & \\
\hline Age, years & & & $0.005^{*}$ \\
\hline Mean \pm SD & $69.0 \pm 14.6$ & $64.0 \pm 14.2$ & \\
\hline Range & $29-87$ & $13-90$ & \\
\hline \multicolumn{4}{|l|}{ Subtypes of glaucoma } \\
\hline Primary open angle glaucoma & $20(25.3)$ & $92(27.0)$ & \\
\hline Exfoliation glaucoma & $19(24.1)$ & $70(20.5)$ & \\
\hline $\begin{array}{l}\text { Primary angle closure } \\
\text { glaucoma }\end{array}$ & $10(12.7)$ & $24(7.0)$ & \\
\hline Neovascular glaucoma & $12(15.2)$ & $96(28.2)$ & \\
\hline Secondary glaucoma & $18(22.8)$ & $59(17.3)$ & \\
\hline Uveitis & $14(17.7)$ & $44(13.0)$ & \\
\hline Others & $4(5.1)$ & $15(4.4)$ & \\
\hline Eye laterality & & & 0.354 \\
\hline Right & $30(38.0)$ & 149 (43.7) & \\
\hline Left & $49(62.0)$ & $192(56.3)$ & \\
\hline $\begin{array}{l}\text { History of previous cataract } \\
\text { surgery }\end{array}$ & & & 0.417 \\
\hline Yes & $34(43.0)$ & $164(48.1)$ & \\
\hline No & $45(57.0)$ & $177(51.9)$ & \\
\hline Preoperative IOP, $\mathrm{mmHg}$ & & & 0.691 \\
\hline Mean \pm SD & $30.7 \pm 9.3$ & $31.4 \pm 9.9$ & \\
\hline Range & $17.7-48.0$ & $6.5-61$ & \\
\hline Postoperative IOP, $\mathrm{mmHg}$ & & & $<0.00 I^{*}$ \\
\hline Mean \pm SD & $9.7 \pm 6.0$ & $13.8 \pm 6.7$ & \\
\hline Range & $0-32.0$ & I.I-38.4 & \\
\hline \multicolumn{4}{|c|}{ Period between the surgery and $C D$, days } \\
\hline Mean \pm SD & $6.1 \pm 3.6$ & & \\
\hline Range & $1-18$ & & \\
\hline \multicolumn{4}{|l|}{ IOP on the first day of $\mathrm{CD}, \mathrm{mmHg}$} \\
\hline Mean \pm SD & $5.5 \pm 3.6$ & & \\
\hline Range & $0-24$ & & \\
\hline $\begin{array}{l}\text { The lowest postoperative IOP, } \\
\mathrm{mmHg}\end{array}$ & & & $<0.00 I^{*}$ \\
\hline Mean \pm SD & $3.9 \pm 3.5$ & $7.9 \pm 4.5$ & \\
\hline Range & $0-18$ & $0-31$ & \\
\hline Postoperative laser suture lysis & & & 0.087 \\
\hline Yes & $19(24.1)$ & $116(34.0)$ & \\
\hline No & $60(75.9)$ & $225(66.0)$ & \\
\hline
\end{tabular}

Note: $* P<0.05$.

Abbreviations: $C D$, choroidal detachment; IOP, intraocular pressure; SD, standard deviation.

with open angle glaucoma demonstrated that older age $(\mathrm{OR}=1.060$ per year increase; $P=0.0040)$ and reduced postoperative IOP $(\mathrm{OR}=0.898$ per mmHg increase; $P<0.0110)$ were risk factors for choroidal detachment as well.

Because choroidal detachment is a transient complication of trabeculectomy, the risk factors for choroidal detachment 
Table 3 Logistic regression analysis of choroidal detachment after trabeculectomy

\begin{tabular}{llll}
\hline Variable & OR & $\mathbf{9 5 \%} \mathbf{C l}$ & P-value \\
\hline Gender (man/woman) & 1.154 & $0.658-2.078$ & 0.6225 \\
Age (year) & 1.028 & $1.008-1.050$ & $0.0068^{*}$ \\
Laterality (right/left) & 0.764 & $0.446-1.290$ & 0.3190 \\
History of cataract surgery & 0.767 & $0.447-1.302$ & 0.3288 \\
Preoperative IOP $(\mathrm{mmHg})$ & 1.010 & $0.982-1.038$ & 0.4679 \\
Postoperative IOP $(\mathrm{mmHg})$ & 0.887 & $0.838-0.934$ & $<0.0001 *$ \\
Postoperative laser suture lysis & 1.007 & $0.531-1.872$ & 0.9816 \\
\hline
\end{tabular}

Note: $* P<0.05$

Abbreviations: $\mathrm{Cl}$, confidence interval; IOP, intraocular pressure; OR, odds ratio.

Table 4 Comparison of patient data between patients with open eye glaucoma in the choroidal detachment and nonchoroidal detachment groups in open angle glaucoma (20l eyes)

\begin{tabular}{|c|c|c|c|}
\hline \multirow[t]{2}{*}{ Characteristic } & \multicolumn{2}{|l|}{ Value (\%) } & \multirow[t]{2}{*}{$P$-value } \\
\hline & $\begin{array}{l}C D(+) \\
(n=39)\end{array}$ & $\begin{array}{l}C D(-) \\
(n=162)\end{array}$ & \\
\hline Gender & & & 0.626 \\
\hline Male & $28(7 \mid .8)$ & $112(69.1)$ & \\
\hline Female & II (28.2) & $50(30.9)$ & \\
\hline Age, years & & & $0.005^{*}$ \\
\hline Mean \pm SD & $75.1 \pm 10.3$ & $69.5 \pm 14.3$ & \\
\hline Range & $40-87$ & $13-90$ & \\
\hline Subtypes of glaucoma & & & 0.385 \\
\hline $\begin{array}{l}\text { Primary open angle } \\
\text { glaucoma }\end{array}$ & $20(5 \mathrm{I} .3)$ & $86(55.8)$ & \\
\hline Exfoliation glaucoma & $19(48.7)$ & $68(44.2)$ & \\
\hline Eye laterality & & & 0.403 \\
\hline Right & $13(33.3)$ & $63(40.9)$ & \\
\hline Left & $26(66.7)$ & $91(59.1)$ & \\
\hline $\begin{array}{l}\text { History of previous cataract } \\
\text { surgery }\end{array}$ & & & 0.641 \\
\hline Yes & $15(38.5)$ & $65(42.2)$ & \\
\hline No & $24(61.5)$ & $89(57.8)$ & \\
\hline Preoperative IOP, $\mathrm{mmHg}$ & & & 0.691 \\
\hline Mean \pm SD & $27.9 \pm 8.4$ & $27.0 \pm 7.7$ & \\
\hline Range & | $4.7-48.0$ & $\mid 3.7-51.0$ & \\
\hline Postoperative IOP, $\mathrm{mmHg}$ & & & $<0.00 I^{*}$ \\
\hline Mean \pm SD & $9.3 \pm 6.6$ & $12.6 \pm 5.6$ & \\
\hline Range & $0-32.0$ & $3.4-33.9$ & \\
\hline \multicolumn{4}{|c|}{ Period between the surgery and $C D$, days } \\
\hline Mean \pm SD & $6.2 \pm 3.6$ & & \\
\hline Range & $1-13$ & & \\
\hline \multicolumn{4}{|c|}{ IOP on the first day of $\mathrm{CD}, \mathrm{mmHg}$} \\
\hline Mean \pm SD & $6.3 \pm 4.4$ & & \\
\hline Range & $0-24$ & & \\
\hline The lowest postoperative & & & $<0.00 I^{*}$ \\
\hline \multicolumn{4}{|l|}{ IOP, $\mathrm{mmHg}$} \\
\hline Mean \pm SD & $3.6 \pm 3.6$ & $7.3 \pm 3.9$ & \\
\hline Range & $0-18$ & $0-20$ & \\
\hline \multicolumn{4}{|l|}{ Postoperative laser suture lysis } \\
\hline Yes & 7 (I7.9) & $60(37.0)$ & $0.023 *$ \\
\hline No & $32(82.1)$ & $102(63.0)$ & \\
\hline
\end{tabular}

Note: $* P<0.05$.

Abbreviations: $C D$, choroidal detachment; IOP, intraocular pressure; SD, standard deviation.
Table 5 Logistic regression analysis of choroidal detachment after trabeculectomy in open angle glaucoma

\begin{tabular}{llll}
\hline Variable & OR & $95 \% \mathbf{C l}$ & P-value \\
Gender (man/woman) & 1.202 & $0.526-2.893$ & 0.6698 \\
Age (year) & 1.060 & $1.021-1.108$ & $0.0040 *$ \\
Laterality (right/left) & 0.670 & $0.296-1.455$ & 0.3211 \\
Subtype (POAG/EXG) & 1.187 & $0.544-2.621$ & 0.6661 \\
History of cataract surgery & 0.496 & $0.215-1.102$ & 0.0905 \\
Preoperative IOP (mmHg) & 1.015 & $0.966-1.065$ & 0.5314 \\
Postoperative IOP (mmHg) & 0.898 & $0.822-0.970$ & $0.0110 *$ \\
Postoperative laser suture lysis & 0.625 & $0.220-1.633$ & 0.3524 \\
\hline
\end{tabular}

Note: $* P<0.05$.

Abbreviations: $\mathrm{Cl}$, confidence interval; EXG, exfoliation glaucoma; IOP, intraocular pressure; OR, odds ratio; POAG, primary open angle glaucoma.

have not been previously analyzed in a large-scale case series. It has been well known that choroidal detachment occurs in hypotonic eyes after intraocular surgeries including trabeculectomy. ${ }^{10,11}$ In our present study, IOPs after trabeculectomy were significantly lower in the choroidal detachment group than the nonchoroidal detachment group. However, seven patients revealed the lowest IOPs of $10 \mathrm{mmHg}$ or higher. This finding suggests that factors other than hypotony might contribute to choroidal detachment. A previous report suggested that older glaucoma patients often encounter choroidal detachment after trabeculectomy. ${ }^{8}$ Jampel et $\mathrm{al}^{8}$ reported that, among the postoperative complications in 300 glaucomatous patients who had recently undergone trabeculectomy, choroidal detachment, synechiae in the anterior chamber, and wound leak were significantly associated with older age. However, the surgical procedure used for the trabeculectomy was not standardized across these studies. Antimetabolites such as MMC and 5-fluorouracil were used in some patients but not in others. Consistent with the previous report, our present study confirmed that older patients are at higher risk for choroidal detachment following trabeculectomy with MMC.

The underlying reason for this trend remains to be determined. However, one of the mechanisms suggested regarding choroidal detachment is that the dissociation in the ciliary body of the hypotonic eye allows the aqueous humor to flow into the suprachoroidal space. ${ }^{12}$ Another explanatory mechanism is that hypotony enhances the vascular permeability of the choriocapillaris. ${ }^{13,14}$ Similarly, the eyes of older individuals might contain relatively fragile connective tissue, which would enhance fluid movement through the uveal tissue and the vascular wall.

Notably, this study had certain limitations because of its retrospective nature. First, we could not quantify the volume or extension of each patient's choroidal detachment. 
We did not distinguish between subtle and massive choroidal detachments. Second, we did not quantify the degree of postoperative inflammation, which increases the vascular permeability of the choriocapillaris. ${ }^{13}$ Further prospective observational studies could help in confirming the validity of our retrospective data.

\section{Conclusion}

In conclusion, the present study revealed that postoperative hypotony and older age led to an increased likelihood of developing a choroidal detachment after trabeculectomy with MMC. These findings could help us in determining the postoperative management of glaucoma patients who have undergone trabeculectomy with MMC.

\section{Acknowledgments}

This study was supported by Grants-in-Aid for Scientific Research from the Ministry of Education, Culture, Sports, Science and Technology (MEXT), Tokyo, Japan. Author contributions: design and conduct of the study (MI, TI, $\mathrm{HT})$; collection and management of the data (AH, KS, SK); analysis (AH, KS, SK, TI); interpretation of the data (all authors); preparation of the first draft of the manuscript (all authors); review and approval of the manuscript (all authors). Additional contributions: Mao Miyagawa, data collection. All procedures conformed to the Declaration of Helsinki, and informed consent for surgical treatments was obtained from all of the patients. The Institutional Review Board of Kumamoto University Hospital, Kumamoto City, Japan, approved the retrospective study protocol.

\section{Disclosure}

The authors report no conflicts of interest in this work.

\section{References}

1. Lamping KA, Bellows AR, Hutchinson BT, Afran SI. Long-term evaluation of initial filtration surgery. Ophthalmology. 1986;93(1): 91-101.

2. Mills KB. Trabeculectomy: a retrospective long-term follow-up of 444 cases. Br J Ophthalmol. 1981;65(11):790-795.

3. Migdal C, Hitchings R. Morbidity following postoperative hypotony after trabeculectomy. Ophthalmic Surg. 1988;19(12):865-867.

4. Seah KL, Prata JA Jr, Minckler DS, Baerveldt G, Lee PP, Heuer DK Hypotony following trabeculectomy. J Glaucoma. 1995;4(2):73-79.

5. Shirato S, Kitazawa Y, Mishima S. A critical analysis of the trabeculectomy results by a prospective follow-up design. Jpn J Ophthalmol. 1982;26(4):468-480.

6. Benson SE, Mandal K, Bunce CV, Fraser SG. Is post-trabeculectomy hypotony a risk factor for subsequent failure? A case control study. BMC Ophthalmol. 2005;5:7.

7. Bellow AR, Chylack LT Jr, Hutchinson BT. Choroidal detachment Clinical manifestation, therapy and mechanism of formation. Ophthalmology. 1981;88(11):1107-1115.

8. Jampel HD, Musch DC, Gillespie BW, Lichter PR, Wright MM, Guire KE; for Collaborative Initial Glaucoma Treatment Study Group. Perioperative complications of trabeculectomy in the collaborative initial glaucoma treatment study (CIGTS). Am J Ophthalmol. 2005;140(1):16-22.

9. Kojima S, Inatani M, Shobayashi K, Haga A, Inoue T, Tanihara $\mathrm{H}$. Risk factors for hyphema after trabeculectomy with mitomycin C. J Glaucoma. Epub January 31, 2013.

10. Ding C, Zeng J. Clinical study on hypotony following blunt ocular trauma. Int J Ophthalmol. 2012;5(6):771-773.

11. Lee JY, Jeong HS, Lee DY, Sohn HJ, Nam DH. Early postoperative intraocular pressure stability after combined 23-gauge sutureless vitrectomy and cataract surgery in patients with proliferative diabetic retinopathy. Retina. 2012;32(9):1767-1774.

12. Pederson JE, Gaasterland DE, MacLellan HM. Experimental ciliochoroidal detachment. Effect on intraocular pressure and aqueous humor flow. Arch Ophthalmol. 1979;97(3):536-541.

13. Capper SA, Leopold IH. Mechanism of serous choroidal detachment; a review and experimental study. AMA Arch Ophthalmol. 1956;55(1): 101-113.

14. Moses RA. Detachment of ciliary body - anatomical and physical considerations. Invest Ophthalmol. 1965;4(5):935-941.
Clinical Ophthalmology

\section{Publish your work in this journal}

Clinical Ophthalmology is an international, peer-reviewed journal covering all subspecialties within ophthalmology. Key topics include: Optometry; Visual science; Pharmacology and drug therapy in eye diseases; Basic Sciences; Primary and Secondary eye care; Patient Safety and Quality of Care Improvements. This journal is indexed on

Submit your manuscript here: http://www.dovepress.com/clinical-ophthalmology-journal

\section{Dovepress}

PubMed Central and CAS, and is the official journal of The Society of Clinical Ophthalmology (SCO). The manuscript management system is completely online and includes a very quick and fair peer-review system, which is all easy to use. Visit http://www.dovepress.com/ testimonials.php to read real quotes from published authors. 